\section{RevistadePolítica Económica y Desarrollo Sostenible}

Centro Internacional de Política Económica para el Desarrollo Sostenible
Revista de Política Económica y Desarrollo Sostenible

EISSN: 2215-4167 • Vol. 7 (1) • Julio-Diciembre, 2021: 1-7

DOI: https://doi.org/10.15359/peds.7-1.3

URL: http://www.revistas.una.ac.cr/politicaeconomica

Revista electrónica semestral publicada por el Centro Internacional de Política Económica para el Desarrollo Sostenible

Universidad Nacional, Lagunilla, Heredia Apartado 2393-3000

\title{
Breve descripción de la situación macroeconómica de Costa Rica en el contexto del COVID-19
}

\author{
Brief description of the macroeconomic situation of Costa Rica in the context of \\ COVID-19
}

Keylin Jiménez Elizondo ${ }^{1}$

iD https://orcid.org/0000-0002-3715-4340

keylinjimeli08@gmail.com

Fecha de recibido: 18 noviembre, 2020 Fecha de corrección: 4 de marzo, 2021 Fecha de aceptación: 9 de setiembre, 2021

\section{Resumen}

La pandemia de COVID-19 afectó de forma directa las economías de los países. Ante este panorama, las políticas económicas recomendadas son diversas; sin embargo, la situación que enfrenta cada país es particular. Por ende, se exponen en este ensayo las políticas más preponderantes a nivel mundial, así como las alternativas dadas por algunos economistas. Se valora, además, la posibilidad de aplicar esas políticas económicas considerando la situación actual del país. Los resultados no son alentadores para Costa Rica: la política fiscal tiene poco margen de acción; por su parte, la política monetaria es una herramienta útil pero insuficiente para hacer frente a todos los problemas del país. Es imperativo para salir de la crisis económica que los cambios por realizar sean estructurales y no solo coyunturales.

Palabras clave: cambio estructural, crisis económica, política fiscal, política monetaria, pandemia,

\begin{abstract}
The COVID-19 pandemic directly affected countries' economies. Given this picture, the recommended economic policies are diverse, but the situation faced by each country is particular. Therefore, the most leading policies in the world, as well as the alternatives given by some economists, are set out in this essay. The possibility of implementing these economic policies is also valued in view of the current situation in the country. The results are not encouraging for Costa Rica: fiscal policy has little scope for action; whereas monetary policy is a useful but insufficient tool to deal with all the country's problems. In order to emerge from the economic crisis it is imperative that the changes to be made are structural and not just conjunctural.
\end{abstract}

Key words: structural change, economic crisis,fiscal policy, monetary policy, Pandemics

1 Estudiante de maestría en Política Económica con énfasis en Desarrollo Sostenible del Centro Internacional de Política Económica para el Desarrollo Sostenible CINPE-UNA. Licenciada en Relaciones Internacionales y bachiller en Economía de la Universidad Nacional. Especialista en Energías Renovables de la EARTH y the Renewables Academy AG. 
Revista de Política Económica y Desarrollo Sostenible • EISSN: 2215-4167

Vol. 7 (1) • Julio-Diciembre, 2021: 1-7

DOI: https://doi.org/10.15359/peds.7-1.3

Jiménez Elizondo

URL: http://www.revistas.una.ac.cr/politicaeconomica

\section{1. ¿Cómo afrontaron la crisis económica a nivel internacional?: Medidas y recomendaciones}

El COVID-19 trajo consigo un panorama inesperado para los diferentes gobiernos del mundo, el cual no solo llegó a generar estragos en la salud de millones de personas, sino también una afectación significativa en la economía de los países. En la crisis se enfrentaron choques externos e internos; por un lado, se experimentó la caída de la demanda externa, y por el otro, una disminución en los ingresos de empresas y hogares debido al cierre de fronteras, confinamiento de la población, cierres temporales de comercios, entre otras. Esta situación afectó la demanda agregada e impactó, además, en la tasa de desempleo.

Salvar la economía al mismo tiempo que se cuidaba la salud de la ciudadanía parecía un objetivo inalcanzable en esta crisis; sin embargo, autores como Richard Baldwin, consideran que esto es un falso dilema, entre sus recomendaciones anota que es posible lograrlo con una política fiscal expansiva, es decir, un aumento del gasto que esté dirigido a apoyar empresas y familias durante el confinamiento. Recalca, además, que para los países ricos no cerrar la economía para no perder dinero deja de ser un asunto económico y se convierte en un tema moral (Baldwin \& Weder, 2020). Pero ¿qué pasa con los países en vías de desarrollo, cuyo déficit fiscal ya ha sobrepasado el porcentaje adecuado y sus posibilidades de incrementar el gasto son reducidas? El autor señala que para estos países la opción más viable es solicitar ayuda financiera a organismos internacionales como el Fondo Monetario Internacional (FMI), que fue precisamente la alternativa considerada por el gobierno costarricense; sin embargo, se presenta una fuerte oposición por parte de otros sectores para implementar esta medida.

La proliferación de ideas para atender la crisis económica y sanitaria no se ha hecho esperar, sin dejar de lado que las recetas mágicas no existen y que las políticas económicas o sanitarias que son efectivas en algunos países no necesariamente tendrán el mismo resultado en Costa Rica. Es primordial contemplar nuestra situación en específico.

Cuando se observa el panorama internacional, el gasto público, así como la inyección de liquidez, se convirtieron en las políticas económicas principales. Alemania es un claro ejemplo de que ahorrar durante la crisis no es una opción; al contrario de su condición habitual, después de varios años presentando un superávit en su resultado primario y financiero, se estimó para 2020 un déficit del 7,5\% del PIB (Europa Press, 2020) como consecuencia de las medidas para atender la pandemia. Este país llevó a cabo una política fiscal expansiva mediante ambas vías: un aumento del gasto y una reducción de impuestos.

Continuando con el continente europeo, se evidenció por parte del Banco Central Europeo también un incremento sustancial en la inyección de liquidez (El Español, 2020), lo cual es una acción poco ortodoxa y que pocas veces caracteriza a este actor del sistema financiero, incluyendo a su actual presidente Christine Lagarde; lo cual nos manifiesta que efectivamente se está viviendo una circunstancia inusual. Estas acciones son también observables en otras regiones del mundo, como América del Norte con Estados Unidos o Canadá, o bien América Latina.

Considerando, entonces, que la fórmula parece ser similar a lo largo del planeta, es necesario preguntarse si estas políticas están siendo las más adecuadas. Stiglitz y Rashid (2020), en su artículo 
"Un estímulo económico que funcione", señalan que las medidas que se han tomado hasta el momento, como la expansión fiscal que recomienda Baldwin, pueden no estar generando el efecto deseado: un incremento en el consumo y en la inversión. Esto se debe a que en un estado de incertidumbre como el actual, los individuos y empresas tienden a ahorrar como una forma de prepararse para lo que vendrá.

Ante este panorama, los autores identifican que la clave se encuentra "en reducir el riesgo y aumentar los incentivos al gasto" (Stiglitz y Rashid, 2020), y mencionan dos medidas:

i. Los títulos contingentes de Arrow-Debreu, instrumentos cuya ejecución estaría supeditada a condiciones predeterminadas.

ii. Vales de gasto para consumo privado.

En el primer caso, se hace referencia a un Estado que brinde algún tipo de garantía para las familias; por ejemplo, la suspensión de pagos mensuales posterior a la compra de un bien, si se presentase algún problema que les impida continuar con la amortización. Lo mismo en caso de préstamos e hipotecas para promover la compra de bienes duraderos, y de igual manera con las empresas; esto con el fin de motivarlas a una mayor inversión. El segundo punto habla de cupones que pueden utilizarse para la compra de bienes y servicios, pero tienen una fecha de caducidad, lo cual promueve el consumo en el corto plazo. Otro punto relevante que anotan en su artículo son los costos sociales que puede implicar el exceso de liquidez en la economía, considerando específicamente las preocupaciones que esto genera sobre la deuda y la inflación.

Sobre este artículo es posible destacar dos aspectos: en primer lugar, las propuestas reflejan un enfoque keynesiano, dado que se orientan a la demanda; además, se espera un papel dinámico del Estado que abogue por políticas fiscales activas. Segundo, es importante considerar los argumentos dados por dos experimentados economistas; no obstante, nuevamente, es vital conocer la situación específica de los países para identificar aquellas políticas que deben ser tomadas en cuenta y otras que, aunque son imperiosas, no siempre son posibles de aplicar.

Dada la descripción anterior sobre las políticas implementadas por las principales economías del mundo y las recomendaciones de diferentes economistas sobre lo que deben realizar los países en desarrollo, es vital identificar la dinámica que se desarrolla aún en el país, con el fin de analizar si es la más apropiada.

\section{El caso costarricense}

Costa Rica, anterior a la presente crisis, enfrentaba ya una difícil situación fiscal que limitaba su accionar en términos de gasto. La reforma fiscal aprobada en el año 2018 permitió un leve aumento en los ingresos, y el déficit primario mostraba un buen desempeño ya que se estimaba una reducción del 1,1\% en 2019 a 0,8\% en 2020 (BCCR, 2020, p. 41); no obstante, la crisis sanitaria y económica causada por el COVID-19 llegó a cambiar las estimaciones realizadas. 
Revista de Política Económica y Desarrollo Sostenible • EISSN: 2215-4167

Vol. 7 (1) • Julio-Diciembre, 2021: 1-7

DOI: https://doi.org/10.15359/peds.7-1.3

Jiménez Elizondo

URL: http://www.revistas.una.ac.cr/politicaeconomica

Como parte de las políticas económicas implementadas por el gobierno se optó por brindar el Bono Proteger, cuyo objetivo era ayudar a aquellas familias desempleadas por un período de tres meses. Adicionalmente, se realizó una moratoria, por el mismo lapso, para el pago de impuestos por parte de empresas. Esto incrementó el gasto y disminuyó la entrada de ingresos.

Conociendo este panorama, es difícil considerar que se puedan promover las medidas señaladas por Stiglitz y Rashid en el contexto costarricense, debido a que el gobierno no cuenta con las condiciones para ofrecer el tipo de garantías que ellos proponen. El margen de acción desde la política fiscal es reducido mientras los ingresos del gobierno no incrementen o sus gastos disminuyan. Respecto a esto, algunos expertos proponen como principal salida la búsqueda de deuda barata que le permita al gobierno reducir el pago por intereses de la actual deuda, y así contar con mayor flexibilidad en términos fiscales, tal como anotan Baldwin \& Weber, en el caso de países en desarrollo.

La política monetaria, por su parte, puede emplearse de forma más amplia. El Banco Central de Costa Rica (BCCR) ha venido realizando un papel importante en su política y ha logrado cumplir con sus objetivos, específicamente en cuanto a la estabilidad de precios. Aunado a lo anterior, la tasa de inflación se encuentra por debajo del rango meta $( \pm 3 \%)$, y se espera que continúe así, debido a la baja en el precio de las materias primas como el petróleo, por lo que no se generará una presión hacia el alza. En términos cambiarios, hasta el momento el tipo de cambio no ha presentado una devaluación significativa que pueda causar efectos importantes sobre la deuda o las importaciones. Adicionalmente, el BCCR cuenta con las reservas necesarias para hacer frente a un choque de este tipo, por lo que es posible aplicar políticas económicas bajo esta directriz sin miedo a una elevada inflación.

Lo anterior muestra que la política monetaria es la principal herramienta para dinamizar la economía. El BCCR ha venido trabajando bajo esta línea, disminuyendo tres veces consecutivas la tasa de política monetaria (TPM); sin embargo, se ha evidenciado que el traspaso de la TPM hacia las tasas de interés no es inmediato, según Barquero y Cendra (2020):

En promedio tarda 7 meses en el caso de las tasas pasivas y 16 meses en las activas. [Además] se encontró evidencia de no linealidad en el traspaso, así como de asimetría; es decir, incrementos en TPM tienden a transmitirse más rápido que disminuciones” (p. 3).

Por esta razón, otras medidas - como los acuerdos tomados entre el BCCR, el Conassif y la Sugefpueden tener un impacto más significativo. Entre los pactos realizados, sobresale la flexibilización de regulaciones prudenciales "orientadas a reducir la cuota de las operaciones crediticias actuales y potenciales" (Conassif, 2020) con el fin de atenuar el deterioro en la capacidad de pago de los hogares y empresas costarricenses. Por otro lado, se han realizado ajustes a normativas que permiten la compra de bonos del gobierno en el mercado secundario, y se han realizado préstamos a la banca para que pueda facilitar el crédito a pequeñas y medianas empresas.

Si bien esto puede contribuir a dinamizar la economía, es necesario realizar acciones que le permitan al país contraer una deuda barata, como se indicó con anterioridad, y a la vez hacer frente 
Revista de Política Económica y Desarrollo Sostenible • EISSN: 2215-4167

Vol. 7 (1) • Julio-Diciembre, 2021: 1-7

DOI: https://doi.org/10.15359/peds.7-1.3

Jiménez Elizondo

URL: http://www.revistas.una.ac.cr/politicaeconomica

a los nuevos gastos. La principal alternativa para Costa Rica es solicitar un préstamo al FMI, medida que se ha planteado ya en dos ocasiones por parte del gobierno; sin embargo, algunos economistas opositores a esta decisión proponen medidas diferentes como i) la compra de bonos en el mercado primario y secundario, ii) la obtención de letras del tesoro, o bien iii) el uso de reservas.

Sobre esto es posible acotar que, en el primer caso, existe una ley que lo prohíbe; mientras que en el segundo caso ya fue modificada, pero aún no ha sido necesario aplicarla. Respecto a las letras del tesoro, se indica "que estas se utilizan en casos excepcionales, ya que envían una señal a los acreedores de que el gobierno no cuenta con más liquidez y esto, además de generar desconfianza, puede empeorar nuestra calificación de riesgo país" (P. Villalobos, comunicación personal, 3 de agosto de 2020). Adicionalmente, hay una ley que indica que la tasa a la que se debe financiar las letras del tesoro no puede ser inferior a la tasa básica pasiva (TBP); asimismo, el préstamo debe ser pagado antes del 31 de diciembre del año en curso.

Por lo anterior, es evidente que resulta más beneficioso adquirir otros créditos de organismos internacionales como el FMI, que se ofrecen a una tasa de $1.5 \%$ inferior a la TBP y a un plazo mayor. En cuanto al uso de reservas, se explica que en primer lugar "las reservas no pertenecen en su totalidad al BCCR: una parte es el encaje legal en dólares de los bancos financieros; también se encuentra dinero del gobierno, que proviene de los préstamos que realizan los acreedores” (P. Villalobos, comunicación personal, 3 de agosto de 2020). Por otro lado, el objetivo de las reservas es evitar una crisis en la balanza de pagos; por ende, de utilizarlas para otro fin, podrían causar problemas a futuro.

Es importante destacar que, si bien, en términos de tasas y plazos el préstamo del FMI resulta una alternativa más viable que las planteadas, estos créditos siempre se acompañan de condiciones que permitan al país ser más eficiente en sus finanzas, pero también requisitos que aseguren que este tendrá la capacidad de reembolsarle los recursos al organismo.

La primera propuesta planteada por Costa Rica para obtener la ayuda económica por parte del FMI no tuvo cabida entre los diferentes sectores del país, debido a que se centraba en un aumento de impuestos y solamente en un $20 \%$ de reducción del gasto. El segundo acuerdo planteado por el gobierno causó menos ruido, pero siempre enfrentó algunos grupos en contra. Es difícil obviar la situación fiscal en la que se encuentra el país y la necesidad de recursos pero, pese a ello, este es el momento ideal para que entre las acciones de política se planteen cambios estructurales y no solo coyunturales, que a mediano plazo generarían una razón de deuda aún mayor.

Se debe atacar la evasión y la elusión antes de incrementar los impuestos; además, es necesario procurar que sean las familias y empresas de mayores ingresos los que más paguen, y no se opte por impuestos regresivos, que solo afectan a las personas de menos recursos. Las medidas deben estar dirigidas a una mayor eficiencia del gasto y a una verdadera dinamización de la economía.

Por otro lado, no basta con conseguir deuda barata; es indispensable renegociar los vencimientos de deuda, ya que las tasas de interés son sumamente altas. Para el corto plazo, el país debe explotar el manejo positivo que se dio de la pandemia, con miras a atraer turistas que confíen en que Costa 
Revista de Política Económica y Desarrollo Sostenible • EISSN: 2215-4167

Vol. 7 (1) • Julio-Diciembre, 2021: 1-7

DOI: https://doi.org/10.15359/peds.7-1.3

Jiménez Elizondo

URL: http://www.revistas.una.ac.cr/politicaeconomica

Rica es un país donde pueden estar seguros aun cuando continúa existiendo el virus. Por ende, el turismo es clave para reactivar la economía. Continuando con esta línea, las nuevas condiciones han potenciado un tipo de turista: los nómadas digitales.

Para Costa Rica es una gran oportunidad ofrecer las condiciones necesarias a estos trabajadores que pueden desarrollar sus labores desde otras partes del mundo; eso sí, es indispensable aumentar la conectividad de banda ancha a internet y la velocidad de transmisión, sobre todo en zonas costeras, que suelen ser los lugares más llamativos para los visitantes extranjeros al país.

\section{Conclusiones}

A nivel general los países y bancos aplicaron medidas semejantes: una política fiscal y monetaria expansiva y contracíclica; sin embargo, en el ámbito específico cada gobierno se debió ajustar a las condiciones que presentaba, razón por la cual medidas como las que señalan Baldwin y Weber o Stiglitz y Rashid no siempre podían ser aplicadas, sobre todo en países en vías de desarrollo y que por lo general detentan un alto déficit fiscal que limita su accionar en cuanto al incremento del gasto, por lo que el estímulo económico que funcione será aquel que se adecúe a las condiciones particulares de cada país.

En Costa Rica, las propuestas de política económica son diversas y provienen de todos los sectores. Es claro que los diferentes actores abogan por sus propios intereses, por lo que en ocasiones se proponen opciones que solo ayudan a unos pocos. También es evidente que muchas de estas alternativas no son estudiadas de forma amplia y, por ende, se desconoce su verdadero impacto en la economía nacional. La situación que atraviesa Costa Rica no es sencilla; el diálogo multisectorial es impostergable, al igual que la ejecución de cambios estructurales que vienen afectando al país desde hace muchos años.

La política fiscal no puede ser aplicada de forma amplia con el déficit fiscal que ostenta el país y la disminución de ingresos ante la crisis económica que enfrentan empresas y ciudadanos. La política monetaria, por su parte, es una herramienta valiosa para dinamizar la economía; aun así, no es suficiente para la creación de empleo ni una mayor estimulación del mercado. Las medidas por establecer para salir de la crisis deben considerar la eficiencia del gasto y una mejor recaudación de los impuestos.

\section{Referencias}

Banco Central de Costa Rica (2020). Revisión Programa Macroeconómico 2020-2021. BCCR. https://activos.bccr.fi.cr/sitios/bccr/publicaciones/DocPolticaMonetariaInflacin/RevsionPrograma_Macroeconomico-2020-2021_informe.pdf

Barquero, J.P y Cendra, L.A. (2020). Traspaso de la politica Monetaria en Costa Rica de 2000 a 2018. Banco Central de Costa Rica. https://repositorioinvestigaciones.bccr.fi.cr/bitstream/ handle/20.500.12506/334/2020-DT-01.pdf?sequence=1\&isAllowed=y 
Revista de Política Económica y Desarrollo Sostenible • EISSN: 2215-4167

Vol. 7 (1) • Julio-Diciembre, 2021: 1-7

DOI: https://doi.org/10.15359/peds.7-1.3

Jiménez Elizondo

URL: http://www.revistas.una.ac.cr/politicaeconomica

Consejo Nacional de Supervisión del Sistema Financiero (2020). BCCR y Conassif acuerdan medidas de politica monetaria y financiera para mitigar impacto económico del covid-19. Conassif. http:// www.conassif.fi.cr/2020/03/16/bccr-y-conassif-acuerdan-medidas-de-politica-monetaria-yfinanciera-para-mitigar-impacto-economico-del-covid-19/

Europa Press (2020). Alemania tendrá un déficit récord de 7,5\% del PIB por gastos de la pandemia. El Confidencial. https://www.elconfidencial.com/economia/2020-06-15/alemania-tendra-deficitrecord-pib-gastos-pandemia_2640016/

Invertia/Agencias (2020). El BCE inyecta un récord de liquidez de 1,3 billones de euros a la banca europea. En "Invertia". El Español. https://www.elespanol.com/invertia/empresas/ banca/20200618/bce-inyecta-record-liquidez-billones-euros-europea/498700638_0.html

Stiglitz, J. y Rashid, H. (2020). Un estímulo económico que funcione. Project Syndicate. https:// www2.project-syndicate.org/commentary/stimulus-policies-must-benefit-real-economy-notfinancial-speculation-by-joseph-e-stiglitz-and-hamid-rashid-2020-06/spanish 